\title{
60 \\ Workforce Implications for the Virtual Manufacturing Environment
}

\author{
Dr. James R, Gray, CMfgE, CQA \\ Professor of Technology \\ gray\$j@nku.edu \\ Northern Kentucky University, Highland Heights, KY, 4107
}

\begin{abstract}
There is a new reality in manufacturing today which calls for a global focus. This focus is upon what may be identified as a virtual manufacturing environment. The driving forces behind the virtual manufacturing environment are: a global economic system, a need for products with the most modern features, a lean and agile delivery system, and the highest quality. This new reality has placed great pressure upon the existing workforce. The need for new or innovative approaches to retrain workers that are in place must be identified. The methodology behind training for the virtual manufacturing environment must be developed.
\end{abstract}

We must examine the need for training in team work within the quality organization and training-the-trainer efforts to support and sustain organizational change. This paper is concerned with how training content can be structured and how Distance Learning technology can be used to establish a Learning Organization. The paper deals with the creation of a Learning Organization, whose purpose is to promote and sustain continuous learning through the use of computer based technology.

\section{UPDATING THE WORK FORCE}

Over the past three decades, U.S. workers with above average education and skills generally have adjusted better to changes in the economy then the less skilled and educated individual in the workforce. The country has had to confront chronic problems with economically and educationally disadvantaged workers. The structure 
of the modern manufacturing economy, based upon rapid technological change, adds new urgency to identifying effective workforce development training and educational approaches.

Perhaps the greatest challenge confronting the workforce today is the declining demand for low skilled workers. More than half of the new employment in the past few years has been in higher paying occupations; only about one fourth of new jobs have been in the low wage category. Most new jobs are concentrated in the managerial, professional, and technical fields, which now comprise over 30 percent of all jobs in the United States. Rapid technological developments, especially in communications and information processing, define many of the skills in demand. In this job market, educated workers with high skills are seeing their earnings increase, but those with less education and fewer skills are experiencing stagnant and even declining real wages.

With the advent of the new reality of a global manufacturing environment, one which puts the U.S. worker in direct skill competition with the workforce of other nations, we must look to new approaches for the education and training of our workers. In particular the low skilled or educationally deficient worker. Methodologies that will deliver quality training programs in the most timely way are needed. Educational technology that allows for the delivery of efficient and effective instruction is necessary if we are to serve our existing workforce.

\section{THE LEARNING ORGANIZATION}

What is needed today is a total and comprehensive orientation to training and education, both on and off the job, in order to capitalize upon the human resource potential available to the labor market. One such approach is what James DeVito calls the "Learning Organization." DeVito has stated that "the learning organization is a relatively new concept that has had a profound effect on how we think about organizational life." He further indicates that "the learning organization concept challenges a company to use knowledge as a basis for its competitive strategy and to see organizational learning as the bedrock for its ability to be truly global."

Dave Gravin defines the learning organization as:

an organization skilled at creating, acquiring, and transferring knowledge, and at modifying its behavior to reflect new knowledge and insights. 
The learning organizations are skilled at five main activities: systematic problem solving, experimentation with new approaches, learning from the experiences and best practices of others, and transferring knowledge quickly and efficiently throughout the organization. By creating systems and processes that support these activities and integrate them into the fabric of daily operations, companies can manage their learning more effectively. ${ }^{2}$

One of the main challenges to the establishment of such an organization within any company is to invision the structure of the educational system which is needed to delivery such an environment. Both DeVito and Gravin advocate the total integration of the education/training activity with the business function of the organization. Naturally, the basis of such an undertaking becomes "knowledge". Knowledge becomes the product and process of our attention. How to structure and deliver knowledge upon demand, instantaneously throughout an organization, is key to the establishment of a Learning Organization. Such a paradigm is offered in figure 1.

\section{KNOWLEDGE}

$\underline{\text { LIVE CLASSROOM }} \longrightarrow \underline{\text { ALTERNATIVE DELIVERY }}$

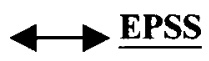

\section{Just-In-Case Training Point-of-Need Training Just-in- Time Support}

Figure 1 Education Support System

As figure 1 suggests, a learning organization requires parallel educational processes that can support and react to delivering knowledge at the time a learner needs information. The more traditional Just-in-Case training occurs through the traditional institutional channels, courses and educational degree programs, based upon the anticipation of knowledge and upon our past experience of need. The Point-of- Need training has been recognized as accessing satellite broadcast, playing video discs, or other self directed learning, delivered closer to the time of need by the learner. Inplant workshops, seminars, and conferences or common training methods are utilized

\footnotetext{
${ }^{2}$ Garvin, D., "Building a Learning Organization", Harvard Business Review, July-August,
} 
for this type of education. Electronic Performance Support Systems (EPSS) provides just enough knowledge, Just-In-Time, for the immediate need of the learner. EPSS is a set of tools that aids the learner in accessing the knowledge and supporting its application in an immediate task. Our need is to integrate these three very different types of educational processes into a total approach. This approach must complement all three processes without interfering with the delivery of any one.

\section{AN INSTRUCTIONAL APPROACH: INTERACTIVE MULTIMEDIA}

The task to deliver knowledge "on demand" in an effective and efficiently way has been greatly aided by the advent of computer aide instruction (CAI). CAI has been in existence for some time within the public educational system, but has not been fully explored by industry as a means of training. What is unique about Interactive Multimedia (IM) is its marriage of computer based training (CBT) and audiovisual (AV) technology, which results in a powerful and flexible delivery method. IM is designed to integrate text, graphics, animation, audio, motion video, and computers so that content can be delivered to the learner in any of the three educational processes above described. Because the knowledge is computer based, learners can interact with it and go through content in a sequence and depth that meets their particular needs. And because IM systems are designed for the micro or personal computers, IM training programs can be used at any point and any time within the organization.

The advantages of IM technology is sighted by Howell and Silvey ${ }^{3}$ as:

1. Meets the individual needs of many learners, accommodating users at all levels of expertise.

2. Lets each user work at the pace that best suits him or her.

3. Offers the best presentation for different subjects.

4. Reverses the traditional student-teacher ratio, bringing many teachers or experts to the individual student.

5. Provides "creative" learning experiences that give each student a continuing functional reason to learn.

${ }^{3}$ Howell, J.J., Silvey, L.O., "Interactive Multimedia Training Systems", The ASTD Training \& Development Handbook, 1996. 
6. Can be designed to encourage learners to explore a topic rather than simply seek a single right answer.

7. Allows learners at different levels to bring their own expertise and creative capabilities into the learning process.

8. Can create a "virtual classroom" wherever a microcomputer or workstation can be placed.

9. Permits small groups of two or three learners to engage in team problem solving

activities.

10. Can function as an in class electronic performance support system, containing

the information, guidance, and tools needed to complete complex activities.

IM educational technology can be imbedded within the firm's computer network, thereby integrating the training activity into the job itself at the point of need. Small units can be delivered the moment the content is needed on the job and at the workstation. In this way, training and job function are considered one in the same by the trainee. IM can move the training activity beyond teaching and into the realm of direct work performance. This is particularly important given that the global economy is moving from an orientation on production towards emphasizing the converting of information to knowledge.

The traditional approaches to training, with its dependence on classroom presentation, becomes too restrictive in the learning organization. The manufacturing organization today presents workers with a challenge to continuously be innovative in the process of solving problems. There are few "right" answers that the worker can depend upon to be so stable that they would never change. This calls for a continuous learning process, with a continuous training process in place for support, to be the goal of training methodology. Within this training system the worker/learner must be in control of the learning process directly, able to analyze the problems at hand, and arrive at reasonable solutions in a systematic way. This, then, becomes the training goal of the learning organization. The learning organization must put in place processes and systems that make it essentially a teaching concern. IM technology delivers the "means" of accomplishing this goal.

\section{INSTRUCTIONAL INFORMATION AND RESOURCES}


The need for firms to obtain the most current information on how to establish a learning organization is crucial. Such information is available in many sources.

Possibly the most up to date information on training and the learning organization would come from the research journals. Several are listed below.

Adult Education Quarterly, American Association for Adult and Continuing Education

Educational Technology, Educational Technology, Inc.

Group \& Organizational Management, Sage Periodicals Press

Human Resource Development Quarterly, American Society for Training and Development

Performance and Instruction, International Society for Performance Improvement

Several more specific IM directed journals are listed below.

Microcomputer Trainer, System Literacy, Inc.

Training, Lakewood Publications

Training and Development, American Society for Training and Development

Workforce Training News: The Newsmagazine for Employee Learning and Development, Enterprise Communication, Inc.

Additionally, professional associations are vital in obtaining the necessary information and direction when implementing the learning organization through IM. Several helpful associations are:

American Society for Training and Development 1640 King Street, Box 1443

Alexandria, VA 22323

American Vocational Association

1410 King Street

Alexandria, VA 22314

Association for Business Simulations and Experiential Learning Center for Business Simulations

Georgia Southern College

Statesboror, GA 30460-8127 
Association for Supervision and Curriculum Development 1250 North Pitt Street

Alexandria, VA 22314

Instructional Systems Association

P.O. Box 1196

Sunset Beach, CA 90742-1196

Organization Development Institute

11234 Walnut Ridge Road

Chesterland, OH 44026

Organization Development Network

P.O. Box 69329

Portland, OR 97201

Society for Applied Learning Technology

50 Culpepper Street

Warrenton, VA 22186

The Internet, with over 22,000 computer and computer networks, represents the prime source for help in establishing a IM based learning organization. The many listservs available on the Internet would be a logical starting point for information. A few would be:

AEE-LIST@PUCC.PRINCETON.EDU ALTLEARN@SJUVM.STJOHNS.EDU ASAT-EVA@UNLVM.UNL.EDU DISRES-L@RYERSON.BITNET HRD-L@MIZZOU1.MISSOURI.EDU TRDEV-L@PSUVM.PSU.EDU list)
(Experiential education list) (Alternative approaches to learning) (Distance education evaluation group) (Distance education research list) (Human resource development group) (Training and development discussions

Another source on the NET would be news groups. The following news groups would have vital information, helpful in the establishment of a training program.
ALT.EDUCATION.DISTANCE
BIT.LISTSERV.ERL-L
BIT.LISTSERV.QUALITY

(Learning over networks)

(Educational technology list)

(Total Quality Management in 
Manufacturing and Service)

MISC.EDUCATION.MULTIMEDIA

COMP.GROUPWARE.LOTUS-NOTES.MISC processes)

\section{CONCLUSION}

If we are to develop educational methodologies that are focused upon today's training needs, than we must look at the environment within which training occurs. We must realize that the manufacturing environment must be seen as a learning environment. This learning environment must be supported by a learning organization, whose purpose is to promote and advance the individual's educational efforts at understanding and using knowledge on an "as needed" basis. The Interactive Multimedia technology systems available today are both efficient and effective at providing the means to delivering this type of learning organization. There is sufficient information, resources, and technology available to us to accomplish this goal.

\section{BIOGRAPHY}

\section{Dr. James R. Gray}

Dr. Gray teaches Manufacturing Engineering and Industrial Technology in the Department of Technology at Northern Kentucky University. He has served the institution for nineteen years. Dr. Gray received his doctorate from West Virginia University and his masters from Western Kentucky University. His undergraduate work was completed at Western Kentucky University in 1971. He is a Certified Manufacturing Engineer, through the Society of Manufacturing Engineers, and is certified as a Quality Auditor by the American Society for Quality Control. He is a qualified Lead Auditor for ISO 9000.

Dr. Gray has over 25 years of experience in education and training in industrial manufacturing subjects. He has specialized in the field of quality control and automated manufacturing processes. Dr. Gray teaches classes such as Quality Control, Manufacturing Processes, Automated Systems, Robotics, etc. He has trained with companies such as Mazak Corporation, Sachs Corporation, Graphic Resources, Esco, F \& N Sheppard, Clarion Corporation, ITT, Rockwell, etc. 